\title{
EDUCAÇÃO EMPREENDEDORA NA EUROPA: UM PANORAMA DE EXPERIÊNCIAS
}

Gracyanne Freire De Araujo ${ }^{1}$

Eduardo Paes Barreto Davel ${ }^{2}$

${ }^{1}$ Universidade Federal de Sergipe/Campus Professor Alberto Carvalho/Departamento de Administração

2 Universidade Federal da Bahia/Programa de Pós-graduação em Administração/Escola de Administração 


\section{EDUCAÇÃO EMPREENDEDORA NA EUROPA: UM PANORAMA DE EXPERIÊNCIAS}

\section{Resumo:}

Este artigo tem como objetivo descrever, sistematizar e discutir as experiências universitárias da educação empreendedora na Europa. Metodologicamente, trata-se de uma pesquisa qualitativa, descritiva-interpretativa, baseada em documentos e entrevistas semiestruturadas com professores e pesquisadores das principais escolas europeias de Administração com enfoque no tema do empreendedorismo. A análise de narrativas do material empírico indica que as experiências da educação para o empreendedorismo podem contribuir para abrir novos caminhos pedagógicos, curriculares, e de estrutura/espaço para uma transformação mais efetiva da educação empreendedora no Brasil.

Palavras-chave: Educação Empreendedora. Empreendedorismo. Escolas Europeias de Administração. Experiências Universitárias.

\section{Introdução}

A discussão sobre educação empreendedora vem se expandindo nos estudos sobre empreendedorismo (Berglund \& Verduijn, 2018; Fayolle, 2018). Dentre os estudos mais discutidos sobre o tema, destacam-se as críticas e os desafios das pedagogias de ensino do empreendedorismo. Pedagogias que vão desde os modelos tradicionais de ensino, com aulas expositivas e a criação de negócios (Morris, Kuratko, \& Cornwall, 2013; Pittaway \& Cope, 2007; Silva \& Pena, 2017), às pedagogias mais inovadoras, que reforçam a concepção da aprendizagem baseada no impacto (Bureau, 2018). Alguns estudiosos consideram o empreendedorismo como um método em si, que requer prática e que por isso não necessita de etapas para ser ensinado (Collins, Smith, \& Hannon, 2006; Neck, Grenee, \& Brush, 2014; Neck, Neck, \& Murray, 2018). Para outros, entender o empreendedorismo como subversão (Bureau \& Komporozos-Athanasiou, 2017) ou como emancipação (Hjorth, 2011) permite aprofundar a aprendizagem do empreendedorismo pela experiência, pela ação-reflexão (Hägg, 2017).

Em suma, constatamos uma diversidade de abordagens sobre educação empreendedora, ao mesmo tempo em que observamos um debate sobre as pedagogias mais utilizadas e importantes para o processo de ensino-aprendizagem do empreendedorismo. Além desse debate, se faz importante também discutir a educação empreendedora pelo discurso hegemônico do empreendedorismo em todo mundo, o que acaba seguindo uma tendência de educação superior baseada em uma reprodução mecanicista do capital (Costa \& Saraiva, 2012). Mas, será que essa diversidade de abordagens pode estar atrelada a uma dificuldade de enquadrar a educação para o empreendedorismo, já que é mais "proveitoso" tirar nossas ideias do campo do empreendedorismo, do que nos voltarmos para a ciência da educação (Kyrö, 2018)? Então, por que não ver isso de perto e entender melhor o que se passa na prática? Este artigo busca contribuir para o avanço do conhecimento sobre educação empreendedora nesse sentido.

O objetivo deste artigo é descrever, sistematizar e discutir as experiências universitárias da educação empreendedora na Europa. Escolheu-se as escolas europeias de Administração, com foco em empreendedorismo, por serem referências, no mundo, em estudos sobre o tema. Além de que, a pesquisadora vivenciou durante 6 meses a rotina acadêmica da Copenhagen Business 
School (CBS), na Dinamarca, o que permitiu realizar pesquisas e visitar as principais universidades europeias: a Lund University e a Stockholm Business University na Suécia, e a Europe Business School (ESCP), na França.

Metodologicamente, este artigo se apresenta como uma pesquisa qualitativa, descritivainterpretativa, baseada em documentos multimodais (Prior, 2003), como os sites oficiais das universidades, blogs, redes sociais e revistas eletrônicas. Tais documentos foram selecionados e analisados previamente, por que representam uma versão particular de realidades construídas (Flick, 2009), a fim de entender os objetivos das escolas de Administração pesquisadas. Cada uma delas foi selecionada de acordo com o seu nível de influência nas pesquisas sobre ensinoaprendizagem do empreendedorismo, currículo, pedagogias de ensino inovadoras e por oferecerem uma estrutura física diferenciada para que os estudantes desenvolvam atividades acadêmicas que proporcionam ensino, pesquisa e prática, como é o caso dos centros de empreendedorismo. As entrevistas semiestruturadas foram realizadas com professores e pesquisadores das universidades visitadas, tornando-se úteis para esta pesquisa por que transmitiram experiências vividas dos entrevistados (Alvesson, 2003) e as informações obtidas foram compreendidas dentro do contexto espaço-temporal em que foram solicitadas e fornecidas (Vergara, 2009).

Nas universidades visitadas foram entrevistados: um professor (Entrevista A) do Department of Management, Politics and Philosophy da CBS, o diretor (Entrevista B) e uma estudante de doutorado (Entrevista C) da Copenhagen School of Entrepreuship (CSE); um professor (Entrevista D) do Department of Business Administration da Lund University, um professor e diretor científico (Entrevista E) do Jean-Baptiste Say Institute da ESCP e uma professora (Entrevista F) da Stockholm Business University. Todas as entrevistas foram conduzidas em 2018. Vale destacar que a indicação dos entrevistados foi orientada pela técnica bola de neve; começou com o professor da CBS que indicou os outros professores que pesquisam e estudam sobre educação empreendedora. Esses outros professores, no momento da entrevista, indicaram outros, o que permitiu confirmar a relevância dos que já tinham sido entrevistados e a de incluir novas pessoas a serem entrevistadas como relevantes.

Este artigo está organizado em três seções, além desta introdução e a conclusão. Na primeira seção apresentamos os centros de educação empreendedora na Europa, justificando a importância de cada um por meio dos objetivos e pedagogias de ensino. Na segunda seção, relatamos a experiência da educação empreendedora nesses centros, desafios e descobertas. Na terceira seção discutimos sobre o que pode ser útil nesses centros para a educação empreendedora no Brasil, sobre os aprendizados e as orientações que podemos ter a partir das experiências europeias.

\section{Centros de Educação Empreendedora na Europa}

Para entender melhor o processo de educação empreendedora dos centros visitados, pesquisamos os sites, blogs e redes sociais dessas instituições. O resultado desta pesquisa demonstrou que estes centros reforçam a ideia de desenvolver pesquisas que ajudem a melhorar a condição de vida da sociedade, ao mesmo tempo que contribuem para capacitar os estudantes em suas habilidades pessoais e profissionais, com foco para criação de negócios inovadores. Fundada em 1917, a Copenhagen Business School (CBS) é uma universidade pública, situada em Copenhague, na Dinamarca, e é considerada uma das mais famosas escolas de negócios da 
Europa. A Copenhagen School of Entrepreuship (CSE), núcleo da CBS, tem se preocupado em desenvolver um processo de ensino-aprendizagem do empreendedorismo diferenciado e promissor para que estudantes, pesquisadores e empresas trabalhem em conjunto. Assim, a CSE é composta por três grandes áreas. A primeira área desenvolve o processo de Incubação de Empresas, a segunda trabalha com as questões acadêmicas, também responsável pela interdisciplinaridade de projetos entre os professores, por meio de cursos e workshops, integrando o tema do empreendedorismo nos currículos em uma ação baseada na aprendizagem e na rede colaborativa de pensamento. A terceira área é responsável pelas relações entre a escola, parceiros externos, universidades, organizações, startups e investidores anjos (Documento institucional, 2019).

O processo de ensino-aprendizagem da CBS oferece um suporte por meio de ferramentas tecnológicas. Elas se enquadram em categorias colaborativas e de aprendizagem baseada em jogos (Documento institucional, 2019). Além dessas ferramentas, a escola também disponibiliza o CBS Studio, um ambiente que ajuda executivos, estudantes e a própria faculdade a desenvolverem um amplo repertório de ideias e ações - Design-thinking (Documento institucional, 2019).

A Lund University também é uma universidade pública, possui três campi localizados em Lund, Helsingborg e Malmö na Suécia. Fundada em 1666, está no ranking entre as 100 melhores universidades do mundo. A visão da universidade é trabalhar para entender, explicar e melhorar o mundo e a condição humana. O plano estratégico é permitir que educação e pesquisa estejam sempre interligadas e estimular a colaboração ativa dos estudantes e pesquisadores para resolver os desafios da sociedade (Documento institucional, 2019).

A Stockholm Business University faz parte da Stockholm University que é uma das maiores e mais prestigiadas escolas de negócios da Escandinávia. A universidade é considerada um ambiente de pesquisa da ciência humana, bem como das pesquisas internacionalmente proeminentes. Fundada em 1878, como uma alternativa radical ao estabelecimento da educação tradicional, a universidade possui um papel significativo de abertura e acessibilidade na sociedade. Possui diversos campi pela Suécia e está entre as 50 melhores universidades da Europa (Documento institucional, 2019).

A Europe Business School (ESCP) é uma escola de negócios europeia com sede em Paris, Londres, Berlin, Madri e Torino. Fundada em 1819, é a escola de negócios mais antiga do mundo e, portanto, apresenta-se como a "The World's First Business School". A missão da ESCP Europe é inspirar e educar líderes empresariais, com a convicção de que eles serão internacionais, digitais e culturalmente eficazes. A abordagem educacional e a estrutura organizacional refletem uma escola integrada com os principais mercados da Europa. A escola considera uma abordagem única de educação e investigação de gestão internacional voltada para a promoção da experiência transnacional, de colaboração e aprendizagem dentro de um contexto pan-europeu (Documento institucional, 2019).

\subsection{Objetivos}

Os objetivos dos centros de empreendedorismo visitados, no geral, possuem objetivos comuns. $\mathrm{Na}$ realidade, os centros buscam ampliar o conhecimento sobre educação empreendedora no meio acadêmico, de forma interdisciplinar, integrando atividades práticas com atividades teóricas. Consequentemente, desenvolvem empreendedores capazes de agir nos aspectos de 
ação-reflexão de forma equilibrada (teoria e prática). Alguns centros enfatizam as atividades de ensino e pesquisa, já outros destacam a importância da criação e expansão de novos negócios. A Copenhagen Business School possui dois objetivos. O primeiro objetivo é apoiar as startups dos estudantes e proporcionar o melhor ambiente para isso. O segundo é apoiar a universidade que ensina empreendedorismo com "casos vivos" e que podem ser utilizados no ensino. A ideia é que os estudantes que quiserem se inserir no espírito empresarial podem ter acesso aos casos vivos. Existe também um "terceiro" objetivo, que é ajudar a CBS a atingir seu objetivo estratégico de ser uma universidade empresarial que apoia e reforça o espírito empresarial e a inovação na sociedade (Entrevista A).

Na Lund University, por exemplo, o objetivo do centro consiste em um conjunto de três atividades. A primeira é a atividade de ensino, com o programa de mestrado (10 a 12 cursos). A segunda atividade é a pesquisa e a terceira é a forte conexão com o mercado (extensão), possuindo profissionais contratados apenas para fazer o contato com empresas/indústrias (Entrevista D). No caso da Stockholm Business University, o objetivo geral é entender o empreendedorismo na sociedade e fazer com que os estudantes sejam mais empreendedores (Entrevista F). Já a Europe Business School tem como foco expandir a internacionalização do programa/cursos. O centro já possui fortes programas de educação empreendedora nos Estados Unidos, Alemanha, Reino Unido (Entrevista E).

\subsection{Pedagogias}

Os centros pesquisados tendem a utilizar pedagogias relativamente convencionais com aulas expositivas, leitura e discussão de textos, uso de casos de ensino, aprendizagem baseada em pesquisa e ações práticas de aprendizagem. No entanto, novas pedagogias também aparecem, com metodologias bem diversificadas do ensino do empreendedorismo. Ao mesmo tempo em que várias especialidades de ensino tornam os centros sem uma abordagem específica.

"Casos vivos", pedagogia de ensino em que visitantes e empresas trazem desafios reais para os estudantes refletirem, aprendizagem baseada em estudo (foco na experimentação e aprendizagem iterativa), e os casos de startup do próprio estudante são pedagogias aplicadas pela CBS. Os estudantes podem também fazer estágios em suas próprias startups, iniciando um negócio e estudá-lo simultaneamente, e desenvolver as habilidades analíticas, com o apoio, é claro, da CSE. Apoiar os processos de startups dos estudantes também é um recurso para ensinar empreendedorismo (Entrevista A).

Um diferencial de educação empreendedora é a que os professores partem de um princípio da ação-reflexão. Uma ação orientada (prática) junto ao mercado e uma reflexão teórica é a pedagogia desenvolvida pela Lund University. Os estudantes possuem uma base sólida de ação orientada e também de reflexão teórica, e muitos já possuem seus próprios negócios, o que permite uma aprendizagem prática. Assim, a educação empreendedora é tratada com o grande foco do aprendizado, um aprendizado prático que ocorre dentro da sala de aula por meio da reflexão, uma análise da teoria, e fora da sala de aula, com a conexão com o mercado (Entrevista D).

Alguns cursos possuem uma visão crítica sobre empreendedorismo. Os currículos usam teóricos da educação, John Dewey e Paulo Freire, como base para a educação empreendedora, como é o caso da Stockholm Business University. Esta escola traz também uma visão mais social e menos capitalista do empreendedorismo, estudando autores das ciências sociais, a 
exemplo de Michel Foucault e Nikolas Rose. No curso de mestrado em empreendedorismo tópicos como neoliberalismo, governabilidade, princípios da potencialidade oferecem aos estudantes um maior entendimento do empreendedor como parte da sociedade. Este tipo de pedagogia de ensino do empreendedorismo é o que constitui de diferente na abordagem com o estudante, apresentando para ele o que realmente é importante para ser um empreendedor (Entrevista F).

O propósito pedagógico de "reperguntar as perguntas" e focar na solução de problemas (problem based learning) é a pedagogia desenvolvida pela ESCP. A escola busca projetos, estudos e trabalhos que possuam um grande impacto junto aos estudantes e a sociedade. Como a paixão é a base do empreendedorismo, perguntar para os estudantes sobre o que é importante para eles, e a partir disso que problemas podem surgir diante deste questionamento é uma pedagogia que vem dando certo para a educação empreendedora desta escola de negócios. $\mathrm{O}$ design-thinking também faz parte do processo de ensino da escola, o que ajuda os estudantes a buscar soluções criativas (Entrevista E).

\section{A Experiência da Educação Empreendedora na Europa}

Os centros de empreendedorismo visitados constituem, no geral, em um espaço físico com salas de aula, organizado em células e vinculados à Escola de Administração ou de Economia ou de Negócios, como costumam chamar. Este vínculo é fortalecido por incubadoras, geralmente denominadas de Centros de Inovação ou Escolas de Empreendedorismo. Entretanto, os estudantes não possuem a necessidade de estarem todos os dias nas escolas de negócios. Eles podem desenvolver os estudos externamente, em empresas, por exemplo. O processo de levar os estudantes para fora da sala de aula, por meio de uma prática empreendedora, faz com que os mesmos possam trabalhar além do contexto de sala de aula, utilizando-se de situações reais. Este processo de educação empreendedora é tão importante para os estudantes, por que podem, assim, se utilizarem da prática.

Além desses ambientes, existem os estúdios, espaços pedagógicos projetados para o processo de aprendizagem empreendedora, onde os estudantes desempenham atividades relacionadas à temática de projetos empreendedores. Estes estúdios são inspirados em design-thinking. $\mathrm{O}$ design-thinking foca no desenvolvimento iterativo de ideias e projetos, o que gera uma cominação de aprendizagem experimental e experiencial. Esses estúdios foram encontrados na CBS e na ESCP Europe.

Este processo de aprendizagem experiencial, desenvolvido em um ambiente propício é crucial para que o estudante crie uma "organização", sendo este o centro do processo empreendedor. Criar uma "organização" é um processo pouco enfatizado dentro do ensino de empreendedorismo. Geralmente, o processo de educação empreendedora está voltado na criação de um negócio, o que omite a natureza do empreendedorismo. Em diversas formas, o processo de criar a "organização" é mais sobre como engajar pessoas, motivar os outros, como inspirar os outros, como trazer atenção para suas ideias e organizar pessoas e recursos para a direção em que se possa tirar benefício. Além de apenas aprender a criar a "organização", o importante também é ser visionário, saber vislumbrar o futuro, lidar com a imaginação e contar história. O estudante precisa ser um bom comunicador e organizador (Entrevista A).

No programa de educação empreendedora, o processo se encontra focado na ação orientada, priorizando a ideia de ter o próprio negócio por parte dos estudantes. É preciso deixar claro para 
os estudantes que apenas ter o negócio não é o mais importante para se ter dinheiro/fortuna. É importante, neste caso, mostrar para os estudantes sobre a reflexão teórica dentro das ações. Muitos dos estudantes continuam sendo empreendedores e a busca do equilíbrio entre ação e reflexão é uma constante no processo de ensino-aprendizagem do empreendedorismo. $\mathrm{O}$ resultado disso, é que os estudantes se tornem empreendedores e reflexivos (Entrevista D).

Quanto à realidade dos estudantes universitários, uma mudança vem ocorrendo no perfil deles durante os últimos 20 anos, o que se torna cada vez mais complicado o processo de ensinoaprendizagem. Isto se deve por que o conhecimento prático dos estudantes não é tão bom como esperado, especialmente nos aspectos relacionados ao conhecimento de engenharia computacional, por exemplo. Isto também se justifica por que na Suécia o conhecimento de engenharia é bastante conectado com a indústria. Os centros de ensino do empreendedorismo necessitam pensar em diferentes termos em relação à pedagogia, sendo necessário uma maior flexibilidade. Como o comportamento dos estudantes mudaram muito, não estão mais acostumados à longas aulas, necessitam de aulas mais rápidas, mais direcionadas ao processo de ação. Sendo assim, os centros precisam ser mais criativos para alcançar a mentalidade dos estudantes do século XXI (Entrevista D).

A experiência como professor de um centro europeu de ensino do empreendedorismo é considerada uma das melhores experiências que um professor universitário poderia apreciar em sua profissão. Ao se perceber, ao ver a si mesmo como um empreendedor, sente-se com isso cada vez mais apaixonado pelo processo de educação do empreendedorismo, pelo empreendedorismo em si e pela equipe envolvida. A experiência nas escolas europeias também oferece uma oportunidade de observar a mudança gradual nas pessoas, nos estudantes, o que é considerada uma rica experiência e de observar que a escola tradicional, por si só, não é suficiente para o processo de educação empreendedora (Entrevista E).

Quanto à questão da criatividade no processo de ensino-aprendizagem do empreendedorismo, os estudantes iniciam o processo com muitas ideias criativas, na maioria das vezes baseadas em suas paixões nos negócios. O processo criativo muda possivelmente as ideias, partindo de ideias mais individuais por ideias mais sociais e amplas (de âmbito social) ao final do curso, por exemplo o de mestrado (Entrevista D).

Para praticar a criação, vale destacar que se faz importante desconstruir o entendimento comum sobre o que é empreendedorismo e entender que não existem regras para empreender. Os estudantes podem tentar de diferentes maneiras e serem livres criando e empreendendo. Por meio de diversas atividades em sala, a criatividade pode ser desenvolvida (Entrevista F).

Metodologicamente se faz necessário não ser criativo, mas praticar criação. O grande objetivo do processo educacional do empreendedorismo está na prática. Assim, existem, necessariamente, três componentes principais no processo da prática da criação: conceito (ler e interpretar), experiência (prática) e o feedback, normalmente por parte dos professores e do mundo real em que os estudantes estão envolvidos fora da sala de aula (Entrevista E).

Como a criatividade, a paixão e a emoção são extremamente importantes no processo de ensinoaprendizagem do empreendedorismo e estão intrínsecas a ele (Entrevista D). A experiência com as artes pode ser uma forma interessante de ser utilizada para trabalhar com diferentes pessoas e consequentemente com diferentes emoções, sempre sentidas em todo o processo, sejam estudantes felizes ou com emoções contrárias de insatisfação dentro do processo de ensinoaprendizagem (Entrevista E). Trabalhar as emoções em sala de aula é uma maneira de trazer 
os estudantes para o contexto de aprendizagem e manter os mesmos curiosos, focados e interessados em abordar o papel da emoção no processo empreendedor (Entrevista F).

\subsection{Descobertas}

Durante as entrevistas, percebemos um contexto da educação empreendedora presente em culturas diferentes. As formas de pensar sobre a educação empreendedora vêm desde uma necessidade de dar um enfoque mais teórico, acadêmico (Entrevista D) até os pensamentos mais passionais sobre o assunto, envolvidos com uma visão para as artes (Entrevistas A e E) e ao mesmo tempo para o mercado. O importante é não deixar de lado a preocupação com o estudante, em saber como ele se colocou e aprendeu nesse processo de ensino-aprendizagem, na satisfação do estudante em se tornar uma pessoa evoluída profissionalmente (Entrevista F). Uma outra descoberta interessante é o fato de que a educação empreendedora tem muito o que se aprender com as artes. A arte se relaciona com a capacidade de gerar afeição, o que se difere da emoção, por ser mais uma forma "supra indivíduo" ou "pré-indivíduo", já a emoção é "individualizada". De forma resumida, a afeição está associada ao social, já a emoção tem a ver com o indivíduo. Essa descoberta foi encontrada na pedagogia dada a CBS, pois uma das missões da escola é promover a visão de afeição entre os estudantes, com foco no social e no processo coletivo. Uma organização onde a afeição foi trabalhada em fases anteriores, os recursos humanos serão mais engajados. A individualização causada pela emoção não é interessante, sendo improdutiva (Entrevistas A e B).

No final de uma experiência de educação empreendedora desses centros, com projetos de ensino prático e reflexivo, não teria como incidir impactos positivos na vida pessoal dos estudantes, como participantes de uma experiência atrelada aos panoramas do mundo das organizações. Todo esse processo de educação empreendedora incrementa o senso de criatividade dos estudantes, potencializa a autoconfiança e aperfeiçoa o conhecimento com a prática e reflexão do ato de empreender.

Diante dessas descobertas, vale uma reflexão: é fundamental humanizar o processo de ensinoaprendizagem do empreendedorismo, enfatizar e dar valor a experiência humana do indivíduo, antes de qualquer processo de ensino-aprendizagem. Esta lógica de pensamento das escolas europeias permite também acreditar que a criatividade está em todos os lugares. Desta maneira, a criatividade se insere nos ambientes, dentro e fora da sala de aula, buscando processos que mudem o mundo. As escolas de negócios ou de empreendedorismo não são ainda totalmente preparadas para o mundo real (Entrevista E).

\subsection{Desafios}

Dentro das experiências educacionais do empreendedorismo nas escolas europeias, os desafios são vastos. A integração das informações adquiridas pelas entrevistas e pelos documentos nos permite apresentar alguns desafios que podem orientar os estudos e pesquisas sobre a educação empreendedora no Brasil. O primeiro desafio é inserir o pensamento reflexivo entre os estudantes durante o processo de ensino-aprendizagem. É fundamental fazer com que a teoria seja mais compreendida e adequar essa teoria aos estudantes. Muitas das teorias ainda utilizadas não são necessariamente baseadas em pesquisas. Muitos modelos teóricos utilizados nunca foram testados por meio de uma pesquisa científica. Este desafio foi mencionado na Lund University (Entrevista D). 
O segundo desafio é em relação ao ensino. É um grande desafio trazer os estudantes para essa linha de pensamento do ensino em si, da importância das aulas, quando os estudantes entram nessa lógica se tornam curiosos, interessados, observam a sociedade contemporânea, suas conexões capitalistas e socialistas e começam a questionar sobre elas. Neste momento, os estudantes passam a ver o empreendedorismo não apenas como montar um negócio, mas como algo parte de uma sociedade do mundo ocidental moderno. Este desafio foi encontrado na Stockholm Business University (Entrevista F). A ausência de uma prática no processo educacional também é considerada por essa universidade. $O$ foco está ainda na formação do indivíduo, sendo este capaz de, ao final do processo, se autogovernar, ser reflexivo, questionador e capaz de se entender como empreendedor para si e para a sociedade (Entrevista F).

No Brasil, diferentemente das universidades pesquisadas na Europa, es escolas de negócios não usam o plano de negócio no processo de ensino-aprendizagem do empreendedorismo (Lima, Lopes, Nassif, \& Silva, 2015), por considerarem uma pedagogia ultrapassada. Esta pedagogia é pensada como um grande gasto de energia pelos estudantes muito mesmo antes de executálo, além de que não se sabe se realmente o que foi planejado (escrito) será executado, ou seja, é um gasto de energia desnecessário antes de colocar o projeto em prática.

Um terceiro desafio estar relacionado a ESCP que é fazer com que os estudantes, em sua totalidade, se insiram na ideia pedagógica e nos objetivos da escola. Um outro desafio é fazer com que alguns professores e pesquisadores da instituição apoiem as ideias e projetos desenvolvidos na escola. Além de que, o suporte funcional não é observado em alguns momentos, especialmente na criação e desenvolvimento de uma exibição/evento com conexão fora da escola (Entrevista E).

O desafio de integrar estudantes, incubadoras, programas e cursos de educação empreendedora da CBS ainda é grande. A incubadora funciona atualmente com orientação externa (clientes, mercado, investidores anjos, investidores em potencial) e estas forças se conectam com os estudantes, chamando a atenção deles. Essa orientação produz um grande potencial de aprendizado. Existe ainda uma conexão na universidade com pessoas interessadas em dar aula de empreendedorismo, dar cursos, participar da incubadora. Tudo isso produz uma dinamização de conhecimento. Ao invés de estudar casos, eles possuem o caso vivo dentro da instituição. A incubadora possui autonomia em relação à escola, assim, um outro desafio é garantir o número de processos que a integram. Desta forma, precisa-se de um maior envolvimento da faculdade na incubadora, envolvimento este baseado em pesquisa, o que eleva a qualidade do ensino. Estes desafios foram destacados na CBS (Entrevistas A e B).

Um outro desafio se insere na concepção da paixão. Como a paixão é a base do empreendedorismo (Cardon, Zietsma, Saparito, Matherne, \& Davis, 2005) faz-se necessário perguntar aos estudantes o que é importante para eles, no que eles são apaixonados. Partindo desse ponto de vista, os estudantes têm a oportunidade de ter uma experiência de criação. Nesse entendimento é que as escolas se apoiam quando o assunto é praticar criação na educação empreendedora, experiência o grande exercício da criação.

Sob este cenário de desafios da educação empreendedora das universidades visitadas, propomos que eles sejam repensados e se transformem em perspectivas futuras sobre a prática pedagógica da experiência nas pesquisas sobre educação empreendedora. 


\section{Discussão}

A educação empreendedora, diante da perspectiva da experiência, orienta os estudantes para o exercício da prática, por meio da elaboração de projetos que sejam viáveis para o mercado/sociedade. A construção do projeto permite que eles tenham uma prática voltada para a reflexão de suas ações, para assim associarem ou buscarem na teoria uma orientação ou soluções para as decisões e problemas no contexto em que projetado. Nesse processo de ensinoaprendizagem do empreendedorismo, os estudantes aprendem a ter uma visão sistêmica de dos negócios, da sociedade e do mundo.

Diversas pedagogias podem ser implementadas de acordo com os objetivos educacionais das instituições de ensino e da cultura local em que estão inseridas. A Figura 1 apresenta uma síntese da educação empreendedora a partir de dois padrões (tradicional e arrojado).

\begin{tabular}{|c|c|c|}
\hline $\begin{array}{c}\text { Centros de } \\
\text { Empreendedorismo }\end{array}$ & $\begin{array}{c}\text { Padrão Tradicional de } \\
\text { Educação Empreendedora }\end{array}$ & $\begin{array}{c}\text { Padrão Arrojado de Educação } \\
\text { Empreendedora }\end{array}$ \\
\hline Objetivos & $\begin{array}{c}\text { Realizar atividades de criação e } \\
\text { expansão de novos negócios. }\end{array}$ & $\begin{array}{c}\text { Reforçar o papel colaborativo e reflexivo do } \\
\text { empreendedor na sociedade. }\end{array}$ \\
\hline Pedagogias & $\begin{array}{c}\text { Aulas expositivas, leitura e } \\
\text { discussão de textos, uso de casos } \\
\text { de ensino, aprendizagem baseada } \\
\text { em pesquisa. }\end{array}$ & $\begin{array}{c}\text { Educação interdisciplinar que integra atividades } \\
\text { práticas e teóricas (ação-reflexão). }\end{array}$ \\
\hline Experiência & Sem destaque. Foco na teoria. & $\begin{array}{c}\text { Aprendizagem experiencial por meio da prática } \\
\text { e conexão com a sociedade. }\end{array}$ \\
\hline Criatividade & $\begin{array}{c}\text { Atividades simples, } \\
\text { desenvolvidas em sala de aula. }\end{array}$ & $\begin{array}{c}\text { Ambientes propícios para praticar criação. } \\
\text { Estímulo e experiência com as artes. }\end{array}$ \\
\hline Emoção & $\begin{array}{c}\text { Sem destaque. Intrínseca ao } \\
\text { processo de ensino- } \\
\text { aprendizagem. }\end{array}$ & $\begin{array}{c}\text { Experiência com as artes para trabalhar com } \\
\text { diferentes emoções, sempre sentidas em todo o } \\
\text { processo de ensino-aprendizagem. }\end{array}$ \\
\hline
\end{tabular}

Figura 1. Padrões de Educação Empreendedora

Fonte: Elaborado pelos autores (2019).

O objetivo de reforçar o papel colaborativo e reflexivo do empreendedor na educação empreendedora arrojada é entender o ato de empreender como um evolutivo processo de construção social (Aldrich, 2003). Essa proposta de educação empreendedora oferece aos estudantes uma conscientização mais ampla das questões sociais que a sociedade enfrenta. Assim, envolve-os no desenvolvimento de conhecimentos sobre como encontrar soluções para essas questões por meio do empreendedorismo (Lindberg \& Schwartz, 2018).

As pedagogias que atendem esse propósito de educação empreendedora arrojada compreendem um processo de ensino-aprendizagem interdisciplinar que integra atividades práticas e teóricas (ação-reflexão). Uma pedagogia baseada na ação-reflexão é a pedagogia intervencionista, entendida como um processo associativo (Resh, Hoyer, \& Steyaert, 2018) na relação entre teoria do empreendedorismo e prática (usando as artes - dança, teatro, música). Outra é a abordagem do aprendizado baseada em impacto (Bureau, 2018), pedagogia que se refere às maneiras pelas quais a aprendizagem é desenvolvida tomando medidas para mudar práticas e hábitos existentes fora do mundo acadêmico. Além disso, o foco no desenvolvimento de conhecimentos e capacidades para a prática pode ser realizada por meio de disciplinas interdisciplinares que ajudem os estudantes a alinharem os resultados com os conteúdos do 
ensino (Grenee, Fetters, Bliss, \& Donnellon, 2018). A pedagogia dialógica é uma pedagogia baseada na ação-reflexão que prima pela posição de ver o mundo a partir de processos dialógicos, que envolvem tensões e conflitos que estão embutidos na produção relacional do discurso e mediados por uma infinidade de artefatos e comportamentos (Bureau \& Komporozos-Athanasiou, 2017). Todas essas pedagogias baseadas na ação-reflexão são exemplos inspiradores para a educação empreendedora que tem como base uma ação orientada e uma reflexão teórica.

Tais pedagogias podem também servir de exemplo para a aprendizagem experiencial por meio da prática e conexão com a sociedade. Tratar da experiência como um elemento chave do processo de educação empreendedora é conceber o empreendedorismo como uma ação experiencial, pois esta ação impulsiona e transforma a sociedade contemporânea. $\mathrm{O}$ intuito de associar empreendedorismo e experiência faz parte de uma ampla discussão sobre a experiência como um processo de "integração criativa" (Brandi, \& Elkjaer, 2016) e representada em significados de ação e prática (Neck et al., 2018).

A criatividade é considerada um elemento estratégico que enriquece a maneira como ensinamos e aprendemos a ser empreendedores. O exercício da criação realizada pelos estudantes é uma forma de experiência que pode ser proporcionada por ambientes propícios para "praticar criação". Esse "praticar criação" está inserido também em um processo de construção social, afetado por fatores sociais e ambientais (Amabile, Barsade, Meuller, \& Staw, 2005). Dentro desse processo é que as práticas artísticas possuem a potencialidade de estimular os estudantes no exercício da criatividade e na experiência de aprendizagem do empreendedorismo (Bureau \& Komporozos-Athanasiou, 2017). Assim, a relação entre práticas artísticas e empreendedorismo se destaca no padrão de educação empreendedora arrojado, por que permite que os estudantes sejam livres para criarem e vivenciarem o empreendedorismo engajando-os em uma ideia de conhecimento social e cultural importante para a construção de profissionais mais humanos.

A experiência com as artes possibilita trabalhar com diferentes emoções, sempre sentidas em todo o processo de ensino-aprendizagem. Essa é uma consideração importante dentro do padrão da educação empreendedora arrojada, por que permite que trocas emocionais entre os estudantes constituídas em uma dinâmica emocional (Liu \& Maitlis, 2014) promove uma aprendizagem pela experiência, oferece uma perspectiva de exercício docente mais consciente e sensível (Canopf, Appio, Bulgacov, \& Camargo, 2018), além de contribuir para uma atitude proativa dos estudantes (Verzat, O’Shea, \& Jore, 2017).

Diante dessa contextualização teórica que permeia o padrão de educação empreendedora arrojado, faz-se necessário, então, trazer também uma discussão sobre como esse padrão se aproxima do padrão de educação empreendedora brasileira. Pesquisar a educação empreendedora no Brasil é um tema considerado promissor (Lopes \& Lima, 2019). Entretanto, é mister também reconhecer qual a forma de empreendedorismo é compreendida e conceituada no Brasil, para entendermos o objetivo que lhe é subjacente. Assim, poderemos entender melhor o que desejamos para os nossos estudantes - formar pessoas que criam uma nova atividade econômica (Davidsson, 2016) ou, por exemplo, seguir uma abordagem mais social e coletiva, ajudando-os a entender o empreendedorismo como construção social (Steyaert \& Hjorth, 2006). Percebe-se que grande parte dos estudos brasileiros sobre educação empreendedora se fixam no primeiro entendimento, por esta razão se faz necessário ir além do entendimento do 
empreendedorismo baseado na identificação e criação de negócios (Lima et al., 2015). Focar nesse propósito, traz uma concepção de educação empreendedora que segue um processo prédefinido de ensino e aprendizagem, engessado em um modelo de negócios (Neck et al., 2018). Será que dessa forma, permitimos que os estudantes vivenciem na prática suas ações e reflitam sobre elas? Será que eles estão refletindo como empreendedores? A deficiência de uma ação orientada para a reflexão é o que carece para os estudantes, que são os verdadeiros protagonistas da educação, se tornem pessoas mais reflexivas sobre seus atos e decidam o que querem para sua carreira profissional e pessoal.

Empreender para a vida, essa é a proposta. Entender o empreendedorismo como emancipação (Rindova, Barry, \& Kentchen, 2009) é o grande desafio da educação empreendedora no Brasil. Compartilhar e experimentar dessas perspectivas de educação empreendedora arrojada pode ser um grande passo para seguir um caminho de avanços de pesquisa e estudos no campo, a fim de tornar uma educação mais criativa para os estudantes, tornando-os mais livres para escolherem o que e como querem empreender em suas vidas, de forma mais humana e responsável.

\section{Conclusão}

O objetivo deste estudo foi apresentar um panorama de experiências universitárias da educação empreendedora na Europa. Para isto, realizamos uma pesquisa descritiva-interpretativa, entrevistando professores/pesquisadores sobre educação empreendedora. Os resultados da pesquisa contribuem para entender o papel do empreendedorismo na sociedade e fazer com que os estudantes sejam mais empreendedores por meio ação-reflexão. Com isso, permite compreender também a mudança de comportamento dos estudantes e na "governamentalidade" (governo do eu, proposto por Nikolas Rose) de si mesmos para atingir a evolução social. O interesse é permitir que os estudantes pensem de forma mais global e social, questionando e refletindo sobre suas ações.

Assim, este estudo traz uma reflexão de desconstrução do entendimento do senso comum do empreendedorismo, de que a proposta do empreendedorismo se limita a abrir um negócio, gerar emprego e renda. Deixar os estudantes livres para pensarem e refletirem sobre empreendedorismo, sem regras, métodos ou processos pré-estabelecidos será uma perspectiva vitoriosa para a educação empreendedora. Estudantes livres, pensam de forma livre, com autonomia para expressarem suas emoções e com isso a praticarem a criação. Aprendem a empreender para a vida.

\section{Referências}

Aldrich, H. E., \& Martinez, M. (2003). Entrepreneurship as a social construction: a multi-level evolutionary approach. In Z. J. Acs \& D. B. Audretch (Org.). Handbook of entrepreneurship research (Chap. 15, pp. 359-399). Kluwer Academic Plubishers: London.

Alvesson, M. (2003). Beyond Neopositivists, Romantics, and Localists: a reflexive approach to interviews in organizational research. Academy of Management Review, 28(1), 13-33. 
Amabile, T. M., Barsade, S. G., Meuller, J. S., \& Staw, B. M. (2005). Affect and creativity at work. Administrative Science Quarterly, 50, 367-403.

Berglund, K., \& Verduijn, K. (2018). Revitalizing entrepreneurship education: adopting a critical approach in the classroom. London: Routledge.

Brandi, U., \& Elkjaer, B. (2016). Management education in a pragmatist perspective after Dewey's experimentalismo. In C. Steyaert, T. Beyes, \& M. Parker (Org.). The Routledge Companion to Reinventing Management Education (Chap. 4, pp. 193-295). New York: Routledge.

Bureau, S. (2018). Learning fictions or facts? Moving from case studies to the impact-based method. In A. Fayolle (Org.). A research agenda for entrepreneurship education (Chap. 12, pp. 243-261). Edward Elgar Publishing Limited: Cheltenham.

Bureau, S., \& Komporozos-Athanasiou, P. (2017). A. Learning subversion in the business school: an 'improbable' encounter. Management Learning, 48(1), 39-56.

Canopf, L., Appio, J., Bulgacov, Y. L. M., \& Camargo, D. (2018). Prática docente no ensino de Administração: analisando a mediação da emoção. Revista Organizações \& Sociedade, 25(86), 371-391.

Cardon, M. S., Zietsma, C., Saparito, P., Matherne, B. P., \& Davis, C. (2005). A tale of passion: New insights into entrepreneurship from a parenthood metaphor. Journal of Business Venturing, 20, 23-45.

Copenhagem Business School. (2019). Recuperado de $<$ http://www.cbs.dk/en/knowledgesociety/businessinsociety/entrepreneurship/education/copen hagen-school-of-entrepreneurship.

CBS Teaching \& Learning. (2019). Recuperado de https://blog.cbs.dk/teach/tools-for-teaching/

CBS Studio. Recuperado dehttps://www.facebook.com/pg/studiocbs/about/?ref=page_internal.

Collins, L. A., Smith, A. J., \& Hannon, P. D. (20016). Applying a Synergistic Learning Approach in Entrepreneurship Education. Management Learning, 37(3), 335-354.

Costa, A. S. M., \& Saraiva, L. A. S. (2012) Hegemonic discourses on entrepreneurship as an ideological mechanism for the reproduction of capital. Organization, 19(5), 587-614.

Davidsson, P. (2016). A "business researcher" view on opportunities for pshychology in entrepreneurship research. Journal of Applied Psychology, 65(3), 628-636. 
ESCP. Europe Business School. (2019). Recuperado de https://www.escpeurope.eu/

Fayolle, A. (2018). A research agenda for entrepreneurship education. Cheltenham: Edward Elgar Publishing Limited.

Flick, U. (2009). Introdução à pesquisa qualitativa. (3a ed.). São Paulo: Artmed.

Grenee, P. G., Fetters, M. L., Bliss, L., \& Donnellon, A. (2018). The future of entrepreneurship education: education for economic and social impact. In A. Fayolle (Org.). A research agenda for entrepreneurship education (Chap. 4, pp. 62-80). Edward Elgar Publishing Limited: Cheltenham.

Hägg, G. (2017). Experiential entrepreneurship education: Reflective thinking as a counterbalance to action for developing entrepreneurial knowledge. Lund: Lund University.

Hjorth, D. (2011). On provocation, education and entrepreneurship. Entrepreneurship \& Regional Development, 23(1-2), 49-63.

Kyrö, P. (2018). The conceptual contribution of education to research on entrepreneurship education. In A. Fayolle (Org.). A research agenda for entrepreneurship education (Chap. 9, pp. 164-186). Edward Elgar Publishing Limited: Cheltenham.

Lindenberg, J., \& Schwartz, B. (2018). Entrepreneurship in societal change: students as reflecting entrepreneurs? In K. Berglund, \& K. Verduijn (Org.). Revitalizing entrepreneurship education: adopting a critical approach in the classroom. (Chap. 2, pp. 43-61). London: Routledge.

Lima, E., Lopes, R. M., Nassif, V., \& Silva, D. (2015). Opportunities to Improve Entrepreneurship Education: Contributions Considering Brazilian Challenges. Journal of Small Business Management, 53(4), 1-19.

Lopes, R. M. A., \& Lima, E. (2019). Desafios atuais e caminhos promissores para a pesquisa em empreendedorismo. Revista de Admisnitração de Empresas, 59(4), 284-292.

Lund University. (2019). Recuperado de https://www.lunduniversity.lu.se/about/about-lunduniversity.

Neck, H. M., Grenee, P. G., \& Brush, C. G. (2014). Teaching entrepreneurship - a practicebased approach. Cheltenham: Edward Elgar.

Neck, H. M., Neck, C. P., \& Murray, E. L. (2018). Entrepreneurship: the practice and mindset. London: SAGE. 
Morris, M. H., Kuratko, D. F., \& Cornwall, J. R. (2013). Entrepreneurship programs and the Modern University. Cheltenham: Edward Elgar.

Pittaway, L., \& Cope, J. (2007). Entrepreneurship education: a systematic review of the evidence. International Small Business Journal, 25(5), 479-510.

Prior, L. (2003). Using documents in social research. London: Sage Publications.

Resh, B., Hoyer, P., \& Steyaert, C. (2018). Between Critique and affirmation: an interventionist approach to entrepreneurship education. In K. Berglund, \& K. Verduijn (Org.). Revitalizing entrepreneurship education: adopting a critical approach in the classroom. (Chap. 9, pp. 178196). London: Routledge.

Rindova, V., Barry, D., \& Kentchen, D. J. (2009). Entrepreneuring as emancipation. Academy of Management Review, 34(3), 477-491.

Silva, J. F., Pena, R. P. M. (2017). O "bê-á-bá” do ensino em empreendedorismo: uma revisão da literatura sobre os métodos e práticas da educação empreendedora. Revista de Empreendedorismo e Gestão de Pequenas Empresas, 6(2), 372-401.

Stockholm University. (2019). Recuperado de https://www.su.se/english/about/facts-figures.

Vergara, S. C. (2009). Métodos de Coleta de Dados no Campo. São Paulo: Atlas.

Verzat, C., O'Shea, N., \& Jore, M. (2017). Teaching proactivity in the entrepreneurial classroom. Entrepreneurship \& Regional Development, 29(9-10), 975-1013. 